\title{
Metformin-induced preferential killing of breast cancer initiating CD44+CD24-/low cells is sufficient to overcome primary resistance to trastuzumab in HER2+ human breast cancer xenografts
}

\author{
Sílvia Cufí⿴囗1, ${ }^{1}$ Bruna Corominas-Faja ${ }^{1,2}$, Alejandro Vazquez-Martinn, ${ }^{1,2}$, Cristina \\ Oliveras-Ferraros ${ }^{1,2}$, Joan Dorca ${ }^{2,3}$, Joaquim Bosch-Barrera ${ }^{2,3}$, Begoña \\ Martin-Castillo ${ }^{2,4}$, Javier A. Menendez ${ }^{1,2}$ \\ ${ }^{1}$ Translational Research Laboratory, Catalan Institute of Oncology (ICO), Girona, Spain \\ ${ }^{2}$ Girona Biomedical Research Institute (IDIBGi), Girona, Spain \\ ${ }^{3}$ Medical Oncology, Catalan Institute of Oncology (ICO), Girona, Spain \\ ${ }^{4}$ Clinical Research Unit, Catalan Institute of Oncology (ICO), Girona, Spain \\ Correspondence to: Javier A. Menendez, email: jmenendez@iconcologia.net; jmenendez@idibgi.org
} Keywords: Metformin, trastuzumab, HER2, cancer stem cells, breast cancer

Received: April 27, 2012, Accepted: April 28, 2012, Published: May 4, 2012

Copyright: ( $)$ Cufi et al. This is an open-access article distributed under the terms of the Creative Commons Attribution License, which permits unrestricted use, distribution, and reproduction in any medium, provided the original author and source are credited.

\section{ABSTRACT:}

Trastuzumab-refractory breast cancer stem cells (CSCs) could explain the high rate of primary resistance to single-agent trastuzumab in HER2 gene-amplified breast cancer patients. The identification of agents with strong selective toxicity for trastuzumabresistant breast CSCs may have tremendous relevance for how HER2+ breast cancer patients should be treated. Using the human breast cancer cell line JIMT-1, which was established from the pleural metastasis of a patient who was clinically resistant to trastuzumab ab initio, we examined whether preferential killing of the putative CD44+CD24-/low breast CSC population might be sufficient to overcome primary resistance to trastuzumab in vivo. Because recent studies have shown that the antidiabetic biguanide metformin can exert antitumor effects by targeted killing of CSClike cells, we explored whether metformin's ability to preferentially kill breast cancer initiating CD44 ${ }^{+}$CD24//low cells may have the potential to sensitize JIMT-1 xenograft mouse models to trastuzumab. Upon isolation for breast cancer initiating CD44+CD24 ${ }^{\prime \prime}$ low cells by employing magnetic activated cell sorting, we observed the kinetics of metformin-induced killing drastically varied among CSC and non-CSC subpopulations. Metformin's cell killing effect increased dramatically by more than 10-fold in CD44+CD24//low breast CSC cells compared to non-CD44+CD24//low immunophenotypes. While seven-weeks treatment length with trastuzumab likewise failed to reduce tumor growth of JIMT-1 xenografts, systemic treatment with metformin as single agent resulted in a significant two-fold reduction in tumor volume. When trastuzumab was combined with concurrent metformin, tumor volume decreased sharply by more than four-fold. Given that metformin-induced preferential killing of breast cancer initiating $\mathrm{CD}^{+} 4^{+} \mathrm{CD} 24^{-/ 1 \text { low }}$ subpopulations is sufficient to overcome in vivo primary resistance to trastuzumab, the incorporation of metformin into trastuzumab-based regimens may provide a valuable strategy for treatment of HER2+ breast cancer patients.

\section{INTRODUCTION}

De novo (i. e. primary) resistance to the monoclonal antibody trastuzumab (Herceptin) remains a prevalent challenge in the treatment of breast cancer patients whose tumors overexpress the human epidermal growth factor 2 (HER2) [1]. Evidence is mounting that the CD $44^{+} \mathrm{CD} 24^{-}$ low cell subpopulation, which is enriched with potential breast cancer stem cells (CSCs), could explain clinical resistance to HER2-targeted therapies [1-3]. Therefore, 
future clinical trials should involve the integration of novel anti-breast cancer stem cells approaches to prevent and overcome the inherent unresponsiveness to trastuzumab across clinically important subgroups of HER2-positive breast cancer patients. Although in vitro studies have recently suggested that the anti-diabetic drug metformin can efficiently eliminate treatment-resistant stem/ progenitor cell populations in heterogeneous breast cancer populations [4-6], it remained to be evaluated whether systemic metformin might overcome primary resistance to trastuzumab in HER2-gene amplified human breast cancer xenografts. Here we explored for the first time the in vivo sensitizing efficacy of metformin on trastuzumab therapy by using xenografts of the human breast cancer cell line JIMT-1, which was established from the pleural metastasis of a patient who was clinically resistant to trastuzumab ab initio [7]. The JIMT-1 model is unique because of displaying at the same time several co-existing mechanisms of resistance to trastuzumab present at variable levels in other breast cancer cell lines, including moderate expression levels of HER2 (despite HER2 gene amplification), low expression of PTEN (phosphatase and tensin homolog), an activating mutation of the $P I K 3 C A$ gene, high expression of NRG1 (neuregulin-1), and enhanced expression of mesenchymal markers, including a naturally enriched subpopulation of breast cancer initiating CD $44^{+} \mathrm{CD} 24^{- \text {llow }}$ CSC-like cells [2, 8-10].

\section{RESULTS AND DISCUSSION}

\section{Metformin preferentially kills breast cancer initiating $\mathrm{CD}^{+} 4^{+} \mathrm{CD} 24-/ \mathrm{low}$ cells}

We first examined whether breast cancer initiating $\mathrm{CD} 44^{+} \mathrm{CD} 24^{-/ \text {low }}$ and non-CD $44^{+} \mathrm{CD} 24^{-/ \text {low }}$ cell subpopulations from the trastuzumab-refractory JIMT-1 cell line exhibited differential sensitivities to the growth inhibitory effects of metformin. We employed MTT-based cell viability assays to compare the degree of sensitivity to metformin of parental JIMT-1 cells and that of JIMT1 cell subpopulations isolated and purified for breast cancer initiating CD $44^{+} \mathrm{CD} 24^{-/ \text {low }}$ and non-CD $44^{+} \mathrm{CD} 24^{-/ \text {low }}$ immunophenotypes by employing magnetic activated cell sorting (MACS; Fig. 1A, top panels). Cells were treated side-by-side on the following sorting day with graded concentrations of metformin for five days. While unsorted JIMT-1, CD $44^{+} \mathrm{CD} 24^{-/ \text {low }}$, and $\mathrm{CD} 44^{+} \mathrm{CD} 24^{+}$populations all showed an inhibitory response to metformin that augmented with the increase in metformin concentration (Fig. 1A, bottom left), each separate cell population differed in their extend of cytotoxic response to metformin. The breast cancer initiating $\mathrm{CD} 44^{+} \mathrm{CD} 24^{-/ \text {low }}$ subpopulation was significantly more sensitive than was the parental or CD $44^{+} \mathrm{CD} 24^{+}$populations. $\mathrm{CD} 44^{+} \mathrm{CD} 24^{-/ \text {low }}$ cells had an estimated $\mathrm{IC}_{50}$ value of $1 \pm 0.2 \mathrm{mmol} / \mathrm{L}$ metformin whereas that in the corresponding non-CD $44^{+} \mathrm{CD} 24^{-/ \text {low }}$ population was $11 \pm 2 \mathrm{mmol} / \mathrm{L}$ metformin (Fig. 1A, bottom right). The $\mathrm{IC}_{50}$ of metformin in the unsorted JIMT-1 parental population was $8 \pm 2 \mathrm{mmol} / \mathrm{L}$ (Fig. 1A, bottom right). These findings, altogether, confirmed that the breast cancer initiating subpopulation within a heterogeneous population of trastuzumab-refractory, HER2-positive breast cancer cells notably exhibit greater sensitivity to the growthinhibitory effects of metformin. Indeed, the growth of the breast cancer initiating $\mathrm{CD} 44^{+} \mathrm{CD} 24^{-/ \text {low }}$ population was more significantly affected by metformin at all tested concentrations. Because it has been shown that gradual loss of stem cell markers takes place in cells growing as a monolayer, these data may further underestimate hypersensitivity of the breast cancer initiating $\mathrm{CD} 44^{+} \mathrm{CD} 24^{-/ \text {low }}$ cells to metformin. Indeed, JIMT-1 cells sorted for the $\mathrm{CD} 44^{+} \mathrm{CD} 24^{-/ \text {low }}$ immunophenotype repopulated all the parental cell fractions after few days in monolayer culture (data not shown).

\section{Systemic metformin inhibits tumor growth in trastuzumab-refractory breast cancer xenografts}

The effects of metformin and trastuzumab alone and in combination on tumor growth were next studied in vivo using a JIMT-1 xenograft animal model (Fig. 1B). Compared to the control group after seven weeks of treatment $\left(940 \pm 170 \mathrm{~mm}^{3}\right)$, the trastuzumab-treated group likewise failed to exhibit significant reductions in mean tumor size $\left(891 \pm 135 \mathrm{~mm}^{3}\right)$. Compared to the mean xenograft tumor size in both the control and the trastuzumab group, the mean tumor size in the metformin group was significantly smaller $\left(390 \pm 64 \mathrm{~mm}^{3}\right)$, which confirmed that the inhibitory effect of metformin at the tested concentration $(250 \mathrm{mg} / \mathrm{kg} /$ day $)$ was notably stronger than that of trastuzumab ( $5 \mathrm{mg} / \mathrm{kg} /$ week) on JIMT-1 tumor growth. When the two drugs were combined, the xenograft tumor size $\left(213 \pm 75 \mathrm{~mm}^{3}\right)$ was smaller than those of the groups treated with trastuzumab or metformin alone, indicating that the combination of the drugs was much more effective at reducing tumor volume. Consequently, the days required for four-fold increase in tumor volume was $27 \pm 5$ after treatment with trastuzumab whereas more than 50 days were required after the combined treatment with trastuzumab and metformin (Fig. 1B). No significant difference in body weight was observed in xenograft tumor-bearing mice between the treatment groups (data not shown).

Our current findings reveal that: a.) Metformin as single agent is active against JIMT-1-derived tumor xenografts with primary resistance to trastuzumab; b.) metformin's ability to distinctively kill breast cancer initiating $\mathrm{CD} 44^{+} \mathrm{CD} 24^{-/ \text {low }}$ mesenchymal subpopulations is sufficient to overcome in vivo primary resistance to 


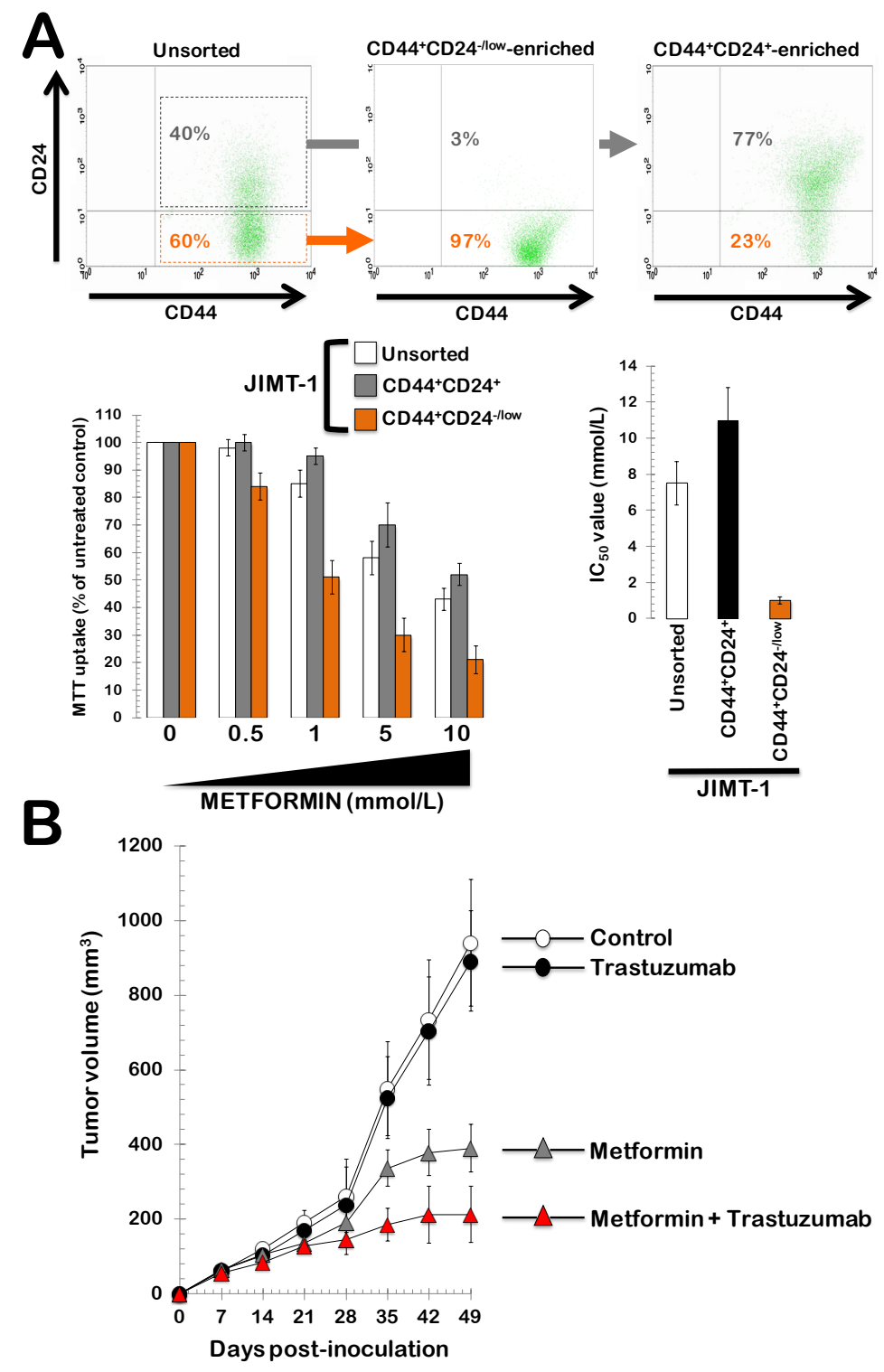

Figure 1: A. Top. CD44 and CD24 expression patterns in $\mathrm{CD} 44^{+} \mathrm{CD} 24^{-/ \text {low }}$ and $\mathrm{CD} 44^{+} \mathrm{CD} 24^{+}$subpopulations of JIMT-1 sorted by sequential sorting (depletion followed by positive selection) using MACS MicroBeads (MACS ${ }^{\circledR}$ Technology). Enrichment of target cells by magnetic MicroBeads was carried out according to the manufacturer's (Milteny Biotec, Bergisch Gladbach, Germany) protocol. $\mathrm{CD} 44^{+} \mathrm{CD} 24^{-/ \text {low }}$ were isolated from the parental JIMT-1 cell line by firstly depleting CD24 $4^{+}$cells using the CD24 MicroBead Kit and then positively selected for CD44 using the CD44 MicroBeads. Cells were fluorescently stained with combinations of fluorochromeconjugated monoclonal antibodies obtained from BD Biosciences (San Diego, CA, USA) against human CD44 (FITC; cat.\#555478) and CD24 (PE; cat.\#555428) or their respective isotype controls. Representative expression (n=5) in pre-sorted and post-sorted JIMT-1 cells is shown. Bottom. Parental JIMT-1 cells and cells sorted for $\mathrm{BCSC}^{+} \mathrm{CD} 44^{+} \mathrm{CD} 24^{- \text {low }}$ and non-BCSC-CD44 $4^{+} \mathrm{CD} 24^{+}$markers were treated simultaneously with increasing concentrations of metformin for 5 days. Cell viability was determined using a standard colorimetric MTT (3-4, 5-dimethylthiazol-2-yl-2, 5-diphenyl-tetrazolium bromide) reduction assay. For each treatment, cell viability was evaluated as a percentage using the following equation: $\left(\mathrm{OD}_{570}\right.$ of treated sample $/ \mathrm{OD}_{570}$ of untreated sample $) \times 100$. Cell sensitivity to metformin was expressed in terms of the concentration of drug required to decrease by $50 \%$ cell viability $\left(\mathrm{IC}_{50}\right.$ value). Since the percentage of control absorbance was considered to be the surviving fraction of cells, the $\mathrm{IC}_{50}$ values were defined as the concentration of agents that produced $50 \%$ reduction in control absorbance. B. Tumor xenografts were established by subcutaneous injection of 5 x $10^{6}$ JIMT- 1 cells suspended in $100 \mu \mathrm{l}$ of culture medium into the flank of female athymic nude mice (four to five weeks old, 23 to $25 \mathrm{~g}$; Harlan Laboratories -France-). Animals were randomized into four groups with five mice in each group: control (vehicles), trastuzumab, metformin, and trastuzumab + Metformin. Trastuzumab (5 mg/kg) was given intraperitoneally (i.p.) once per week. Both the "metformin group" and the "trastuzumab + metformin group" received daily a single i.p. injection of metformin $(250 \mathrm{mg} / \mathrm{kg})$. Mice were weighed once per week after dosing, tumors were measured daily with electronic callipers, and tumor volumes were calculated using the following formula: volume $\left(\mathrm{mm}^{3}\right)=1 \mathrm{ength}$ $x$ width $^{2} x$ 0.5. Figure shows mean tumor volumes $( \pm \mathrm{SD})$ of JIMT-1 xenograft-bearing nude mice following injection with trastuzumab, metformin, and trastuzumab + metformin until seven weeks. 
trastuzumab in HER2-gene amplified breast tumors. A combination of trastuzumab and metformin may provide a valuable strategy for treatment of HER2-overexpressing breast cancer, and a phase II trial recently has opened in Spain to evaluate the efficacy of trastuzumab plus metformin as neo-adjuvant therapy for patients with HER2-positive breast cancer [11].

\section{ACKNOWLEDGMENTS}

This work was financially supported through funding from the Instituto de Salud Carlos III (Ministerio de Sanidad y Consumo, Fondo de Investigación Sanitaria (FIS), Spain, Grants CP05-00090 and PI06-0778 and RD06-0020-0028), the Fundación Científica de la Asociación Española Contra el Cáncer (AECC, Spain), and the Ministerio de Ciencia e Innovación (SAF200911579, Plan Nacional de I+D+ I, MICINN, Spain). Alejandro Vazquez-Martin received the Sara Borrell postdoctoral contract (CD08/00283, Ministerio de Sanidad y Consumo, Fondo de Investigación Sanitaria-FIS-, Spain). Sílvia Cufí received a Research Fellowship (Formación de Personal Investigador, FPI) from the Ministerio de Ciencia e Innovación (MICINN, Spain).

\section{CONFLICT OF INTEREST}

The authors declare no conflict of interest.

\section{REFERENCE}

1. Bedard PL, Cardoso F, Piccart-Gebhart MJ. Stemming resistance to HER-2 targeted therapy. J Mammary Gland Biol. 2009; 14:55-66.

2. Oliveras-Ferraros C, Vazquez-Martin A, Martin-Castillo B, Cufí S, Del Barco S, Lopez-Bonet E, Brunet J, Menendez JA. Dynamic emergence of the mesenchymal CD44(pos) CD24(neg/low) phenotype in HER2-gene amplified breast cancer cells with de novo resistance to trastuzumab (Herceptin). Biochem Biophys Res Commun. 2010; 397:2733.

3. Fumagalli D, Michiels S, Sotiriou C. CD44+ CD24-/low phenotype and resistance to trastuzumab in HER2-positive breast cancer cell lines. Pharmacogenomics. 2011; 12:1213.

4. Hirsch HA, Iliopoulos D, Tsichlis PN, Struhl K. Metformin selectively targets cancer stem cells, and acts together with chemotherapy to block tumor growth and prolong remission. Cancer Res. 2009; 69:7507-7511.

5. Vazquez-Martin A, Oliveras-Ferraros C, Del Barco S, Martin-Castillo B, Menendez JA. The anti-diabetic drug metformin suppresses self-renewal and proliferation of trastuzumab-resistant tumor-initiating breast cancer stem cells. Breast Cancer Res Treat. 2011; 126:355-364.
6. Iliopoulos D, Hirsch HA, Struhl K. Metformin decreases the dose of chemotherapy for prolonging tumor remission in mouse xenografts involving multiple cancer cell types. Cancer Res. 2011; 71:3196-3201.

7. Tanner M, Kapanen AI, Junttila T, Raheem O, Grenman S, Elo J, Elenius K, Isola J. Characterization of a novel cell line established from a patient with Herceptin-resistant breast cancer. Mol Cancer Ther. 2004; 3:1585-1592.

8. Rennstam K, Jönsson G, Tanner M, Bendahl PO, Staaf J, Kapanen AI, Karhu R, Baldetorp B, Borg A, Isola J. Cytogenetic characterization and gene expression profiling of the trastuzumab-resistant breast cancer cell line JIMT-1. Cancer Genet Cytogenet. 2007; 172:95-106.

9. Köninki K, Barok M, Tanner M, Staff S, Pitkänen J, Hemmilä P, Ilvesaro J, Isola J. Multiple molecular mechanisms underlying trastuzumab and lapatinib resistance in JIMT-1 breast cancer cells. Cancer Lett. 2010; 294:211-219.

10. Oliveras-Ferraros C, Vazquez-Martin A, Martin-Castilló B, Pérez-Martínez MC, Cufí S, Del Barco S, Bernado L, Brunet J, López-Bonet E, Menendez JA. Pathway-focused proteomic signatures in HER2-overexpressing breast cancer with a basal-like phenotype: new insights into de novo resistance to trastuzumab (Herceptin). Int J Oncol. 2010; 37:669-678.

11. Martin-Castillo B, Dorca J, Vazquez-Martin A, OliverasFerraros C, Lopez-Bonet E, Garcia M, Del Barco S, Menendez JA. Incorporating the antidiabetic drug metformin in HER2-positive breast cancer treated with neo-adjuvant chemotherapy and trastuzumab: an ongoing clinical-translational research experience at the Catalan Institute of Oncology. Ann Oncol. 2010; 21:187-189. 